\title{
Simulation of natural ventilation of different configurations of a room equipped with a solar chimney under the city of Ouarzazate (Morocco) climatic conditions
}

\author{
Aboubakr Herouane ${ }^{1 *}$, Thami Ait Taleb ${ }^{1}$, and Mourad Taha Janan ${ }^{2}$ \\ ${ }^{1}$ ERME, Department of Physics- Chemistry, Polydisciplinary Faculty of Ouarzazate, Ibn Zohr \\ University, Morocco \\ ${ }^{2}$ Advanced Technical Teachers Training School, Mohammed V University, Rabat, Morocco. \\ *Corresponding author:herouaneaboubakr@gmail.com
}

\begin{abstract}
Natural ventilation is considered as an effective way to improve ventilation and thermal comfort and reduce energy consumption in residential buildings. In this sense, natural ventilation is done by a solar chimney. It is used to increase the air flow through the room by converting thermal energy into kinetic energy. In this work, we intend to present the results of a three dimensional numerical simulation by ANSYS software of natural ventilation through a room equipped with a solar chimney in semiarid climatic conditions of Ouarzazate (Morocco). The chimney is modelled by a rectangular channel with two South-East oriented glass faces. The main objective is to investigate effects of room dimensions for a solar chimney with of fixed dimensions. We also investigate effects of air velocity, turbulence of kinetic energy and air-flow rate in each area of room and solar chimney and determine optimal dimensions of solar chimney for each room size.
\end{abstract}

\section{Nomenclature}

$\mathrm{U}_{\mathrm{i}}$ velocity magnitude $(\mathrm{m} / \mathrm{s})$

$\mathrm{X}, \mathrm{Y}, \mathrm{Z}$ Cartesian coordinates $(\mathrm{m})$

$v$ kinematic viscosity $\left(\mathrm{m}^{2} / \mathrm{s}\right)$

$\lambda$ thermal conductivity $\left(\mathrm{W} \cdot \mathrm{m}^{-1} \cdot \mathrm{K}^{-1}\right)$

$\mathrm{C}_{\mathrm{p}}$ heat capacity $\left(\mathrm{J} \cdot \mathrm{kg}^{-1} \cdot \mathrm{K}^{-1}\right)$

$\rho$ air density $\left(\mathrm{kg} / \mathrm{m}^{3}\right)$

$\mathrm{k}$ pressure loss coefficient

g gravitational acceleration $\left(\mathrm{m} / \mathrm{s}^{2}\right)$

$\mathrm{T}$ Temperature $\left({ }^{\circ} \mathrm{C}\right)$

$\mathrm{P}$ pressure $(\mathrm{Pa})$

$\mathrm{P}_{\mathrm{m}}$ pressure in reference state of the fluid $\left(\rho_{0}, \mathrm{~T}_{0}\right)(\mathrm{Pa})$

$\beta$ coefficient of thermal expansion $\left(\mathrm{K}^{-1}\right)$

$\mathrm{K}$ thermal diffusivity of the fluid $\left(\mathrm{m}^{2} \cdot \mathrm{s}^{-1}\right)$ 


\author{
$\delta$ Kronecker symbol \\ $\mathrm{Z}$ height (m) \\ ACH Air change per hour
}

\title{
1 Introduction
}

Natural ventilation is considered as an effective way to improve ventilation and thermal comfort and reduce energy consumption in residential buildings. In order to well improve natural ventilation, we can use the solar chimney. It is used to increase the air flow through the room by converting thermal energy into kinetic energy. It generates air movement under buoyancy forces that hot air rises and exits from the top of chimney cavity, drawing cooler air into building with continuous cycle [1]. In this context Mekkawi et al. [2] simulated natural ventilation through a solar chimney in Egypt. Their study showed that the installation of the solar chimney of size of $\left(0.4^{\times} 1.5 \mathrm{~m}\right)$ can decrease the temperature from $29.45^{\circ} \mathrm{C}$ to $28.64^{\circ} \mathrm{C}$ in the room and increase the air velocity with $50 \%$. Also, Kasim et al. [3] investigated the effect of different opening positions on natural ventilation. The study is based on nine different positions of two openings located on two opposite walls. The result of this study shows that the air flow rate is maximal when both openings are located at the top of the air flow level. In the same context Zavala-Guillén et al. [4] conducted a numerical study on the optimal width of a solar chimney used for the diurnal cooling of a room, their study showed that the optimal width of the solar chimney for to have an air flow greater than $0.1072 \mathrm{Kg} / \mathrm{s}$ is $0.125 \mathrm{~m}$ with a height of $2 \mathrm{~m}$, and a solar flow of $700 \mathrm{~W} / \mathrm{m} 2$. Some studies $[5,6]$ suggest a cavity gap of 0.2 to $0.3 \mathrm{~m}$ for the solar chimney to achieve maximum performance. Jiménez et al. [7] carried out a study on the performance of a solar chimney installed on a room. The results of the study show that the ventilation rate increases with $45 \%$ in summer and $24.89 \%$ in the winter and the air speeds in summer and winter vary from $0.16 \mathrm{~m} / \mathrm{s}$ to $0.22 \mathrm{~m} / \mathrm{s}$, thus the temperature at the room level varies between $29.5^{\circ} \mathrm{C}$ and $40.5^{\circ} \mathrm{C}$ in the summer and between $16^{\circ} \mathrm{C}$ and $26{ }^{\circ} \mathrm{C}$ in the winter. Cheng et al. [8] conducted a study on optimizing design of solar chimney for natural ventilation and smoke exhaustion, they was developed an empirical model to predict the flow rate through air inlet under both normal and fire conditions, they found that the empirical model can be used for a solar chimney with an up to $0.3 \mathrm{~m}$ cavity gap. Kong et al. [9] investigated a CFD based approach for determining the optimum inclination angle of a roof-top solar chimney for building ventilation in different climate zones in Australia, their results show that the solar chimney with $45^{\circ}$ to $60^{\circ}$ inclination angles results in the maximum ACH on a yearly average basis, And under a given received heat flux, a higher inclination angle results in a better ventilation performance. Villagran et al. [10] also developed the effect of shape and design of Arc greenhouse roof openings on natural ventilation. They investigated three types of greenhouses, the traditional Colombian wood (TG) greenhouse, Gothic and Arc multi-span greenhouses that are characterized by having larger ventilation areas both on the sides and on the roof. Ahmed Abdeen et al. [11] examined numerically and experimentally the efficiency of using an inclined solar chimney to elevate indoor air motion. The solar chimney used is $1.85 \mathrm{~m}$ height, $2.65 \mathrm{~m}$ width, $75^{\circ}$ inclination angle and $0.28 \mathrm{~m}$ air gap. The work found that the width is the most significant parameter, and is found as well that the solar chimney in these dimensions is able to induce air motion of up to $0.28,0.47$ and $0.52 \mathrm{~m} / \mathrm{s}$ at mean solar radiation values of 500,700 and $850 \mathrm{~W} / \mathrm{m}^{2}$, respectively. Leila et al. [12] presented a design of solar chimney connected to a wind catcher and spraying water system for use in a 2-story office under hot and dry climate conditions. The results showed that even on a hot and sunny day, the connection comprising solar chimney, wind catcher and water spray was able to provide proper thermal and air flow conditions for both floors 
through natural convection. The connected system reduced average temperature by $5.2{ }^{\circ} \mathrm{C}$ and provided around $9 \mathrm{~m} 3$ air changes per hour during the hottest hours of the day for the mentioned space. The optimal connected system also saved $75 \%$ of the overall cooling and $90 \%$ of the required ventilation energy during the working time in the peak hours during summer. Nguyen et al. [13] carried out a study of various parameters (absorber surface length, air channel gap, and height and width of the inlet and outlet sections) and heat flux factor effects on the thermal performance of chimney, The results demonstrated that the increase in these parameters resulted in a higher flow rate with negligible impact on the thermal efficiency. It was also understood that a large amount of outlet width resulted in a low flow rate. Samsudin et al. [14] studied the effect of solar radiation on the efficiency of the solar chimney installed in hospitals in Malaysia, the results of their study indicate that the air velocity and the air flow rate increase simultaneously with the increase of solar radiation. Kashyap et al. [15] evaluated the effect of the solar chimney on the natural ventilation of buildings in different areas of India, their results indicate that the optimal dimensions of the solar chimney to have a minimum ACH of 6.20 are $2.5 \mathrm{~m}$ in length, $2 \mathrm{~m}$ wide and $0.1 \mathrm{~m}$ gap, so the solar chimney is efficient in all climatic zones and throughout the year, an energy saving of $89 \mathrm{kWh} /$ year is observed.

Ouarzazate city is among the cities of Morocco that are characterized by their arid climate: In summer, the temperature often exceeds $40^{\circ} \mathrm{C}$, which requires continuous ventilation throughout the day. To address this need, natural ventilation may be the best solution to stabilize temperature and regulate thermal comfort in residential buildings in this city. So, this study presents the results of a numerical simulation under climatic conditions of Ouarzazate city by the ANSYS (fluent) software of the natural ventilation of a threedimensional room equipped with a solar chimney. Thus, we try to study the air velocity, the turbulence of kinetic energy and the air-flow rate in each area of the room and solar chimney, then to determine the optimal dimensions of the solar chimney for each room size.

\subsection{Physical model}

The physical configuration is shown in Figure 1; it is a square room of variable side $(3 \mathrm{~m}$, $4 \mathrm{~m}, 5 \mathrm{~m})$ with a fixed height of $3 \mathrm{~m}$. The window size was kept constant with a dimension of $1 \mathrm{~m} \times 1 \mathrm{~m}$. The height of the solar chimney is $1 \mathrm{~m}$ and the width is $0.3 \mathrm{~m}$. The fluid inside the cavity is the air which considered Newtonian and incompressible, since we study the heat transfer that occurs only by natural convection, the Boussinesq approximation is considered.

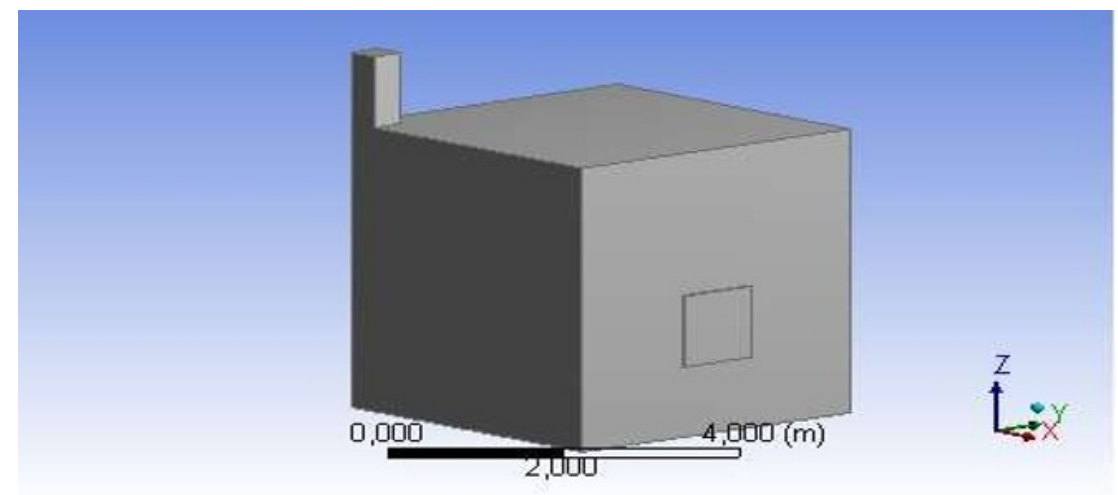

Fig.1. Physical model of the studied configuration 
For the simplification of the problem, the following assumptions are taken a count:

$\checkmark$ The fluid is Newtonian and incompressible.

$\checkmark \quad$ The flow is unsteady.

$\checkmark \quad$ The inlet pressure equal to the atmospheric pressure

$\checkmark \quad$ The outside temperature is constant at $313 \mathrm{k}$.

$\checkmark$ The air flow is considered turbulent.

$\checkmark$ Normal direct solar irradiation is $1423 \mathrm{~W} / \mathrm{m}^{2}$

\subsection{Mathematical model}

Equation representing the conservation of the mass (Continuity) is :

$$
\frac{\partial \mathrm{u}_{\mathrm{i}}}{\partial \mathrm{x}_{\mathrm{i}}}=0
$$

Where $u_{i}$

are the velocity components in $\mathrm{x}, \mathrm{y}, \mathrm{z}$ directions

Equation representing, the momentum ( Navier - Stokes):

Considering the linear variation of the density of the Boussinesq approximation, we obtain the following momentum equation:

$$
\frac{\partial u_{i}}{\partial t}+\frac{\partial\left(u_{i} u_{j}\right)}{\partial x_{j}}=-\frac{1}{\rho_{0}} \frac{\partial p_{m}}{\partial x_{i}}+\frac{\partial}{\partial x_{j}}\left(v\left(\frac{\partial u_{i}}{\partial x_{j}}+\frac{\partial u_{j}}{\partial x_{i}}\right)\right)+g \beta\left(T-T_{0}\right) \delta_{i z}
$$

With:

$\checkmark \quad \mathrm{P}_{\mathrm{m}}=\mathrm{p}+\rho_{\mathrm{o}} \mathrm{gz}$ : the pressure corresponding to the reference state of the fluid $\left(\rho_{0}\right.$, $\mathrm{T}_{0}$ ), $v$ the kinematic viscosity and $\mathrm{g}$ the gravitational field.

$\beta$ : the coefficient of thermal expansion at constant pressure. It describes the change of volume at constant pressure as a function of temperature.

Energy equation:

This equation is deduced from the first principle of thermodynamics by neglecting the effect of pressure in front of temperature variation. It is then expressed by:

Where:

$$
\frac{\partial(T)}{\partial t}+\frac{\partial\left(u_{j} T\right)}{\partial x_{j}}=\frac{\partial}{\partial x_{j}}\left(k\left(\frac{\partial T}{\partial x_{j}}\right)\right)
$$

$\boldsymbol{k}=\frac{\lambda}{\rho \boldsymbol{C}_{\boldsymbol{p}}}$ is the thermal diffusivity of the fluid $\left(\mathrm{m}^{2} \cdot \mathrm{s}^{-1}\right), \mathrm{C}_{\mathrm{p}}$ is the heat capacity $\left(\mathrm{J} \cdot \mathrm{kg}^{-1} \cdot \mathrm{K}^{-1}\right)$ and $\lambda$ is the thermal conductivity $\left(\mathrm{W} \cdot \mathrm{m}^{-1} \cdot \mathrm{K}^{-1}\right) \cdot[16]$

All these equations are taken into account in the program which is part of the software used for the simulation.

In this study, we used a tetrahedron-type mesh with a high number of mesh nodes, access to 99487 nodes, as it is shown in figure 2. After having carried out several attempts and mesh tests in order to choose the optimal mesh which should give a good precision on the speed of the air and on the flow of air, we opted for an optimal choice which is composed of 562130 elements. 


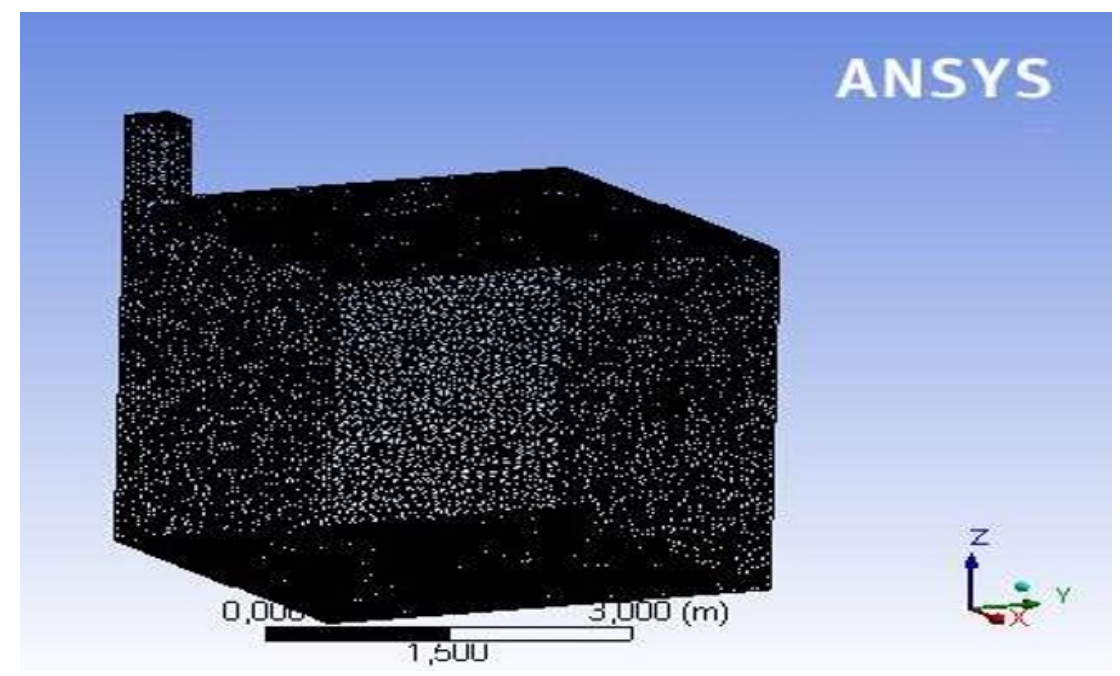

Fig.2. Mesh of the model

\section{Results and discussion}

$>$ Air velocities, turbulence of kinetic energy and Air flow rate in different plane of the room of $3 \mathrm{~m}$ in dimensions.

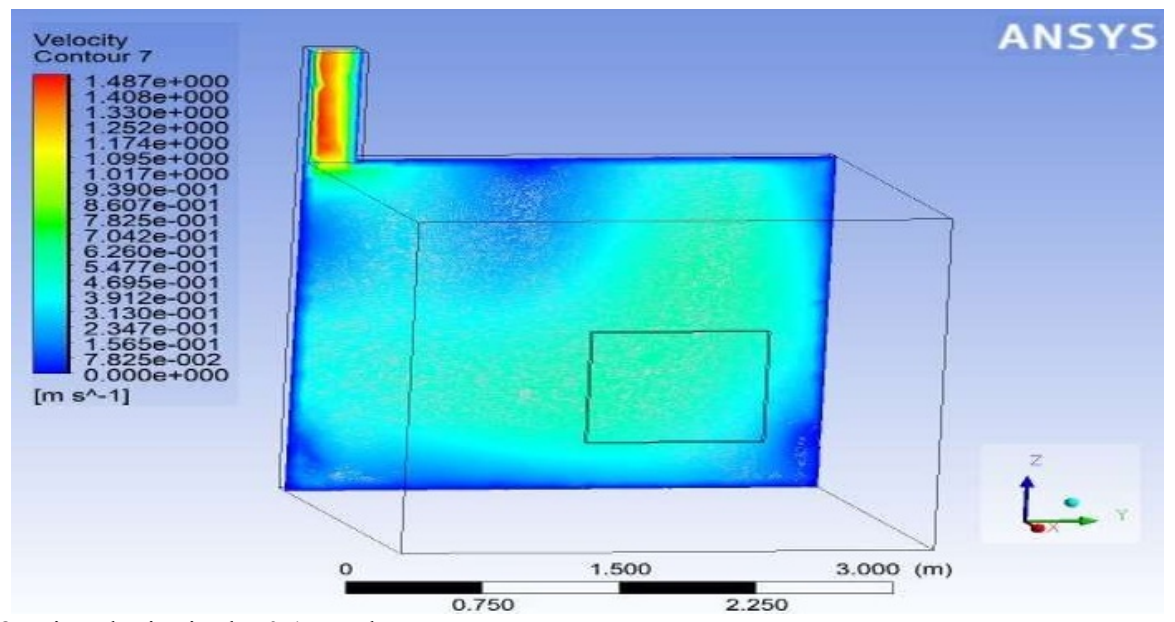

Fig.3. Air velocity in the $0.15 \mathrm{~m}$ plane 


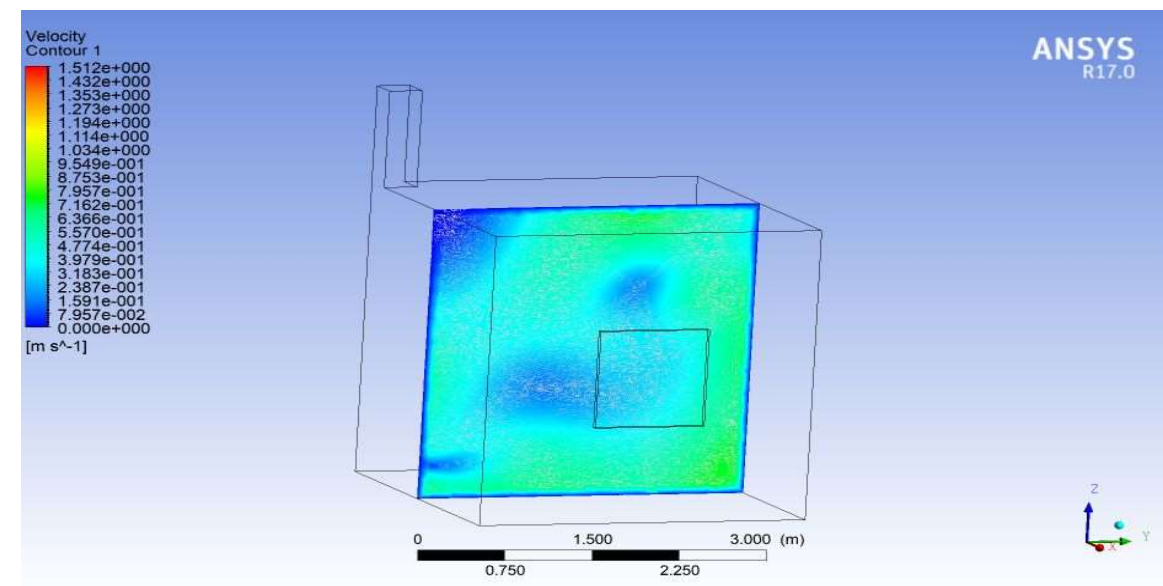

Fig.4. Air velocity in the $1.5 \mathrm{~m}$ plane

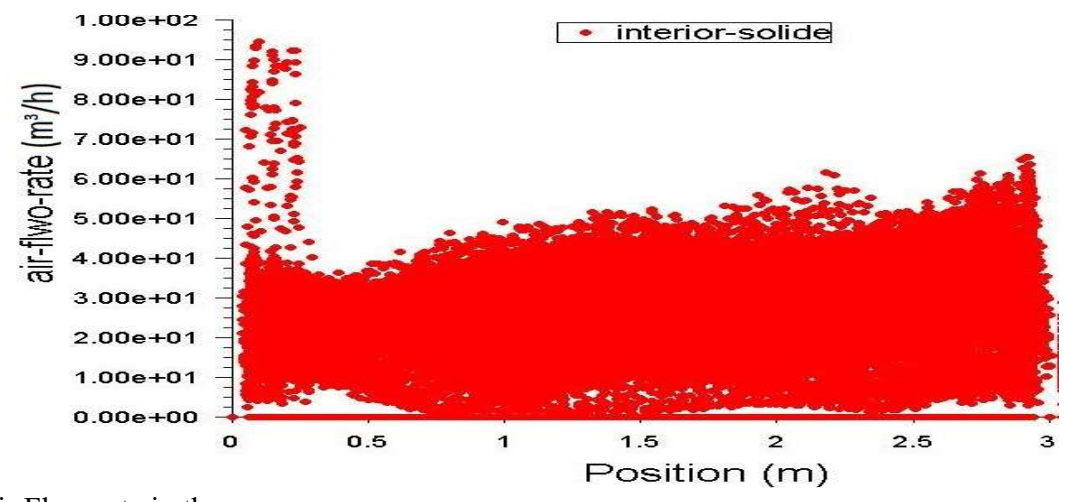

Fig.5. Air Flow rate in the room

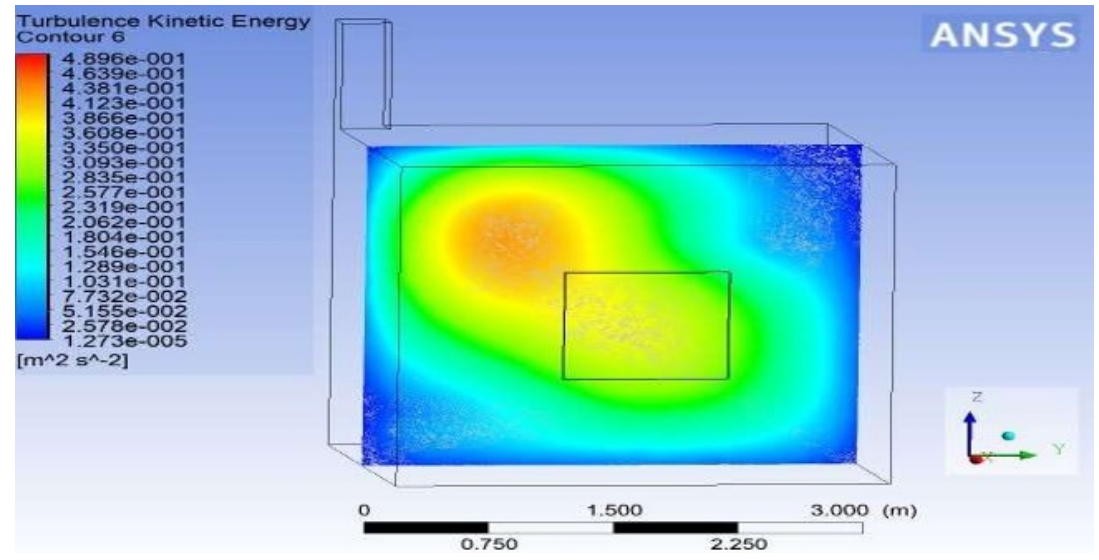

Fig.6.Turbulence of kinetic energy in the $1.5 \mathrm{~m}$ plane

In these figures we can note that the air velocity increases from the entrance of the window towards the exit of the solar chimney. So it is maximum in the chimney $1.48 \mathrm{~m} / \mathrm{s}$. the air velocity is also important in the middle of the room $0.87 \mathrm{~m} / \mathrm{s}$, but it's low in the top and bottom of the room. The more important is that the air velocity increases in all direction of the room and create a passive cooling. The air flow rate is greatly increased at the solar 
chimney $90 \mathrm{~m}^{3} / \mathrm{h}$, and also very high at the level of the whole of room $40 \mathrm{~m}^{3} / \mathrm{h}$, that makes more effective natural ventilation for the turbulence of kinetic energy its value is low, which allows the room to be naturally ventilated perfectly.

Air velocities, turbulence of kinetic energy and air flow rate in different plane of the room of $4 \mathrm{~m}$ in dimensions.

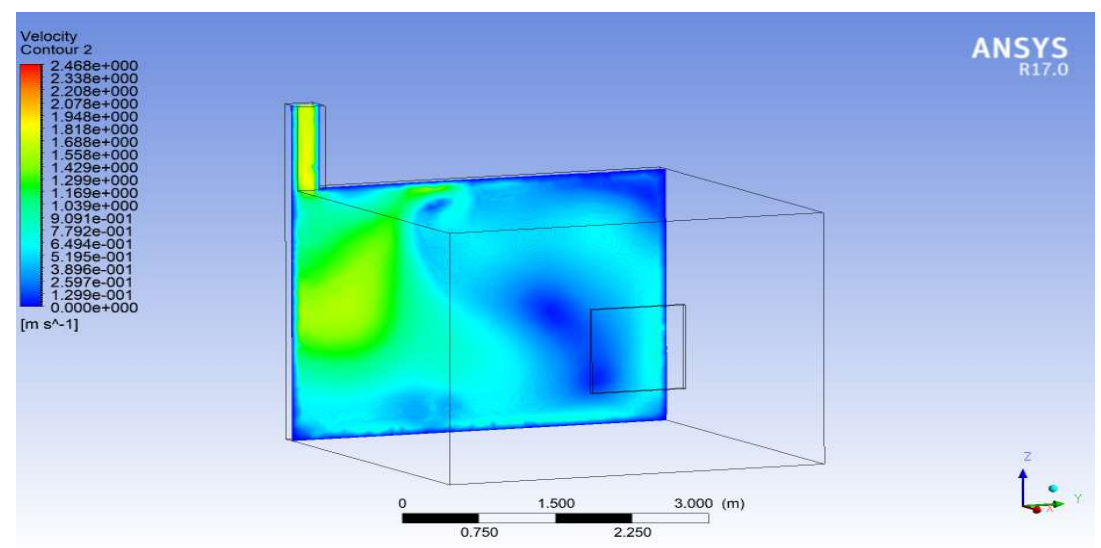

Fig.7.Air velocity in the $0.15 \mathrm{~m}$ plane

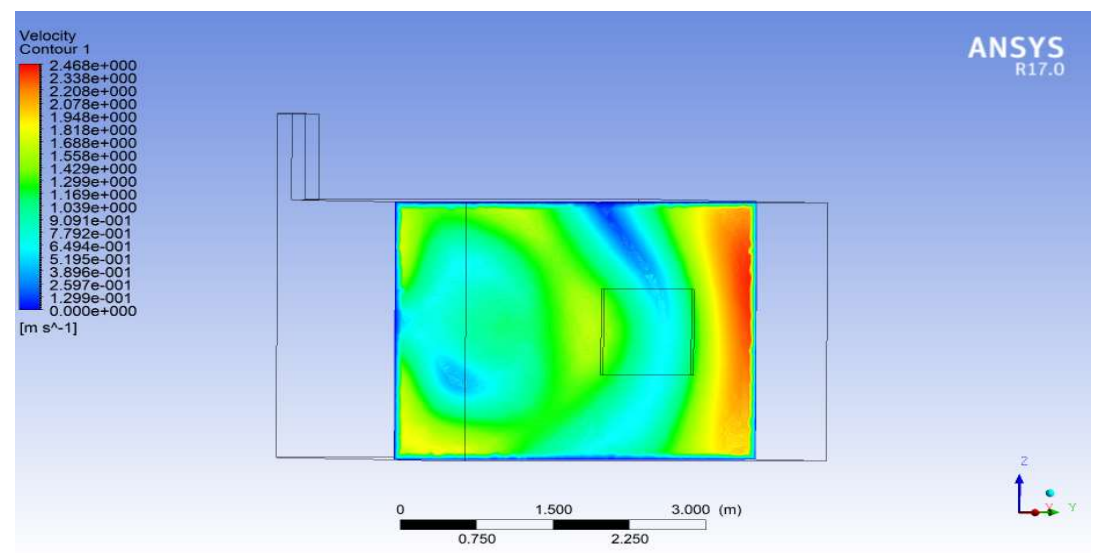

Fig.8.Air velocity in the $2 \mathrm{~m}$ plane 


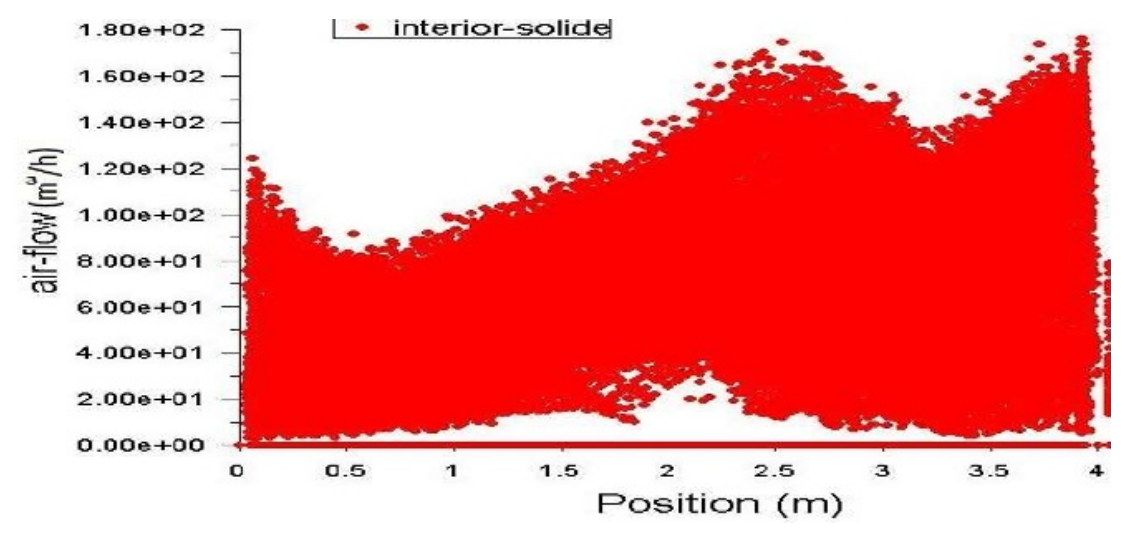

Fig.9.Air flow rate in the room

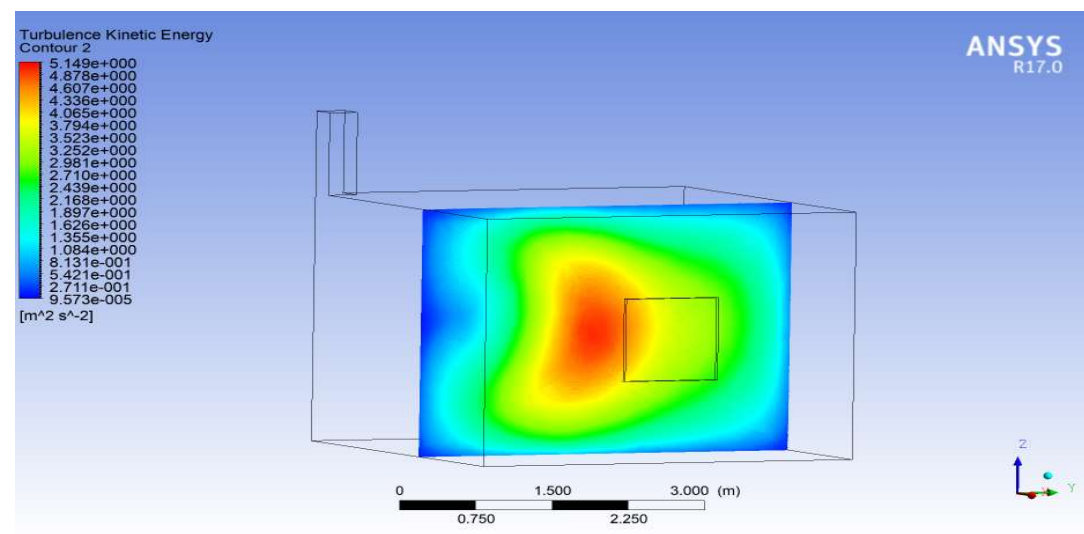

Fig.10.Turbulence of kinetic energy in the $2 \mathrm{~m}$ plane

This figures show that's the air velocity gradually increases in the solar chimney, which causes the circulation of the air inside the room. We notice that the air velocity is maximum in the middle of the room $2.88 \mathrm{~m} / \mathrm{s}$ and increases from bottom up to the horizontal plane of the room, and then it decreases to the ceiling. For the air flow rate it is found that it varies in proportion to the air velocity, it is higher in the middle plane of the room $180 \mathrm{~m}^{3} / \mathrm{h}$ as well in the solar chimney $120 \mathrm{~m}^{3} / \mathrm{h}$. The turbulence of the kinetic energy is also high throughout the room and it is maximum in the horizontal plane of the window $5.15 \mathrm{~m}^{2} / \mathrm{s}^{2}$. All that makes the room ventilated naturally.

Air velocities, turbulence of kinetic energy and Air flow rate in different plane of the room of $5 \mathrm{~m}$ in dimensions. 


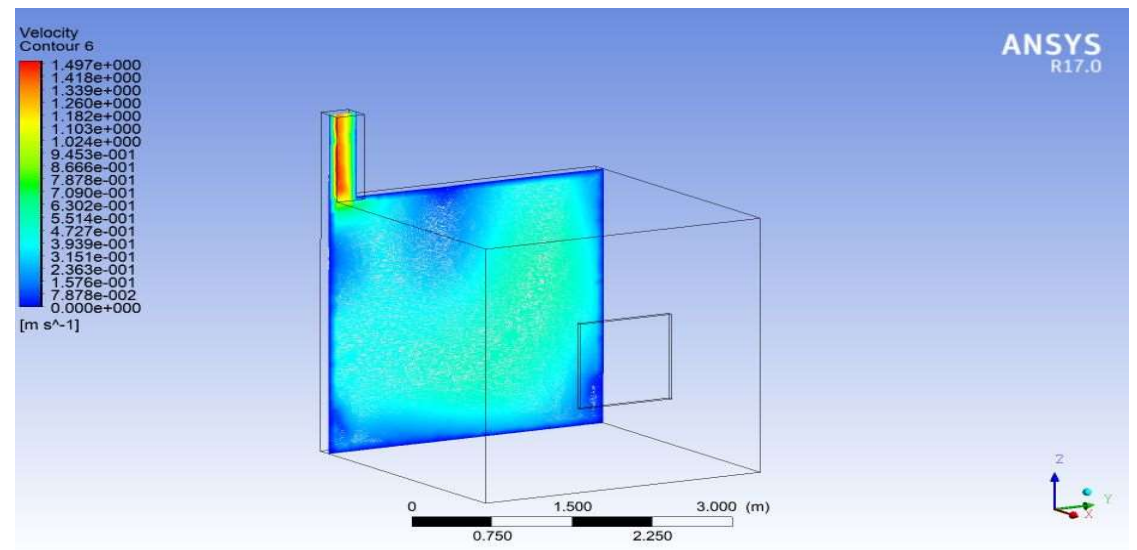

Fig.11.Air velocity in the 0.15 plane

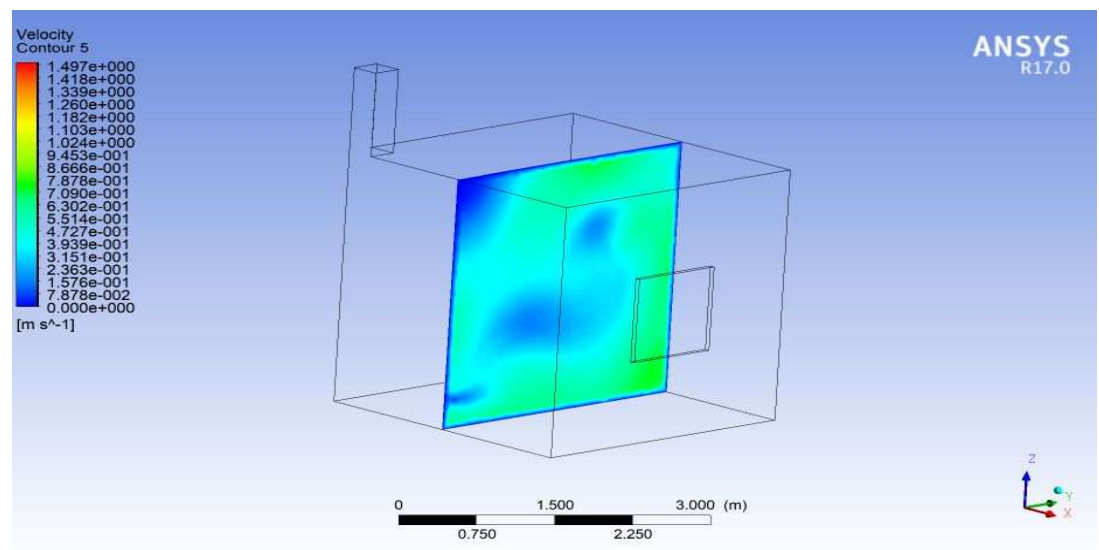

Fig.12. Air velocity in the $2.5 \mathrm{~m}$ plane

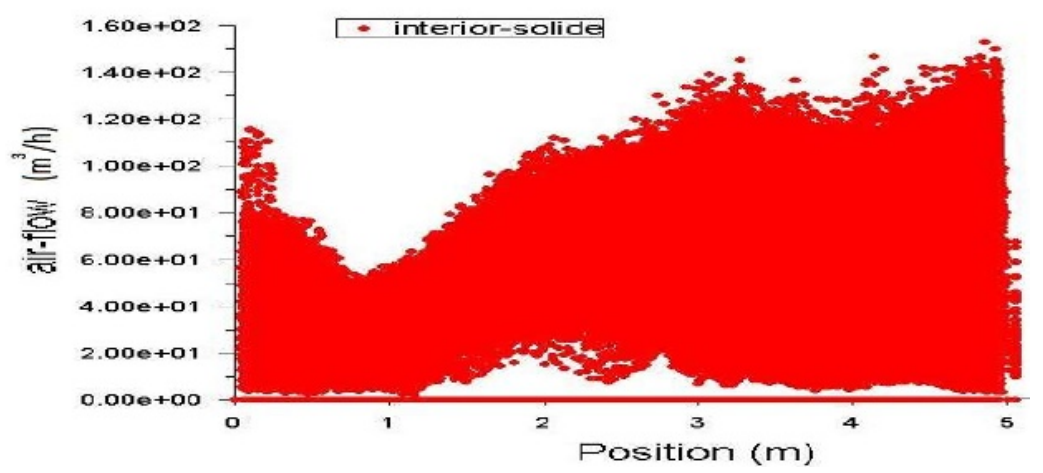

Fig.13. Air Flow rate in the room 


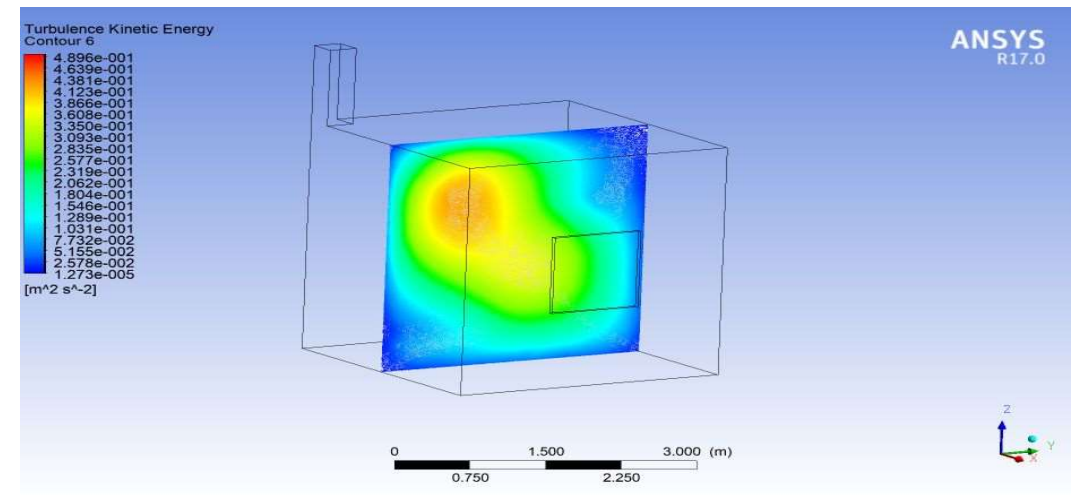

Fig.14.Turbulence of kinetic energy in the $2.5 \mathrm{~m}$ plane

These results show clearly that the air velocity increase from the inlet of the window to the outlet of the solar chimney for which is maximum $1.49 \mathrm{~m} / \mathrm{s}$, it is also medium in all direction of the room and very low in the top and bottom of the room. We notice that the air flow rate is high in the room and the chimney, its maximum value is $140 \mathrm{~m}^{3} / \mathrm{h}$. the turbulence of the kinetic energy also is high its maximum value is $48 \mathrm{~m}^{2} / \mathrm{s}^{2}$. This values show the capacity of solar chimney to improve the thermal comfort in the building by making continuously the movement of air in the building.

By comparing the results of the three simulations, we can see that the air velocity, the air flow rate and the turbulence of the kinetic energy increase simultaneously when we pass from the room of $3 \mathrm{~m}$ in dimension to the room of $4 \mathrm{~m}$, but contrary when we pass from the room of $4 \mathrm{~m}$ to the room of $5 \mathrm{~m}$ we can note that they decrease. These results confirm that the solar chimney of $0.3 \mathrm{~m}$ of width could be designed to the room of $4 \mathrm{~m}$ in dimensions.

\section{Conclusion}

This work present a numerical simulation under climatic conditions of Ouarzazate city by the ANSYS (fluent) software of the natural ventilation of a three-dimensional room equipped with a solar chimney.

The results of the study show that solar chimney has an important role to increase natural ventilation in the room. The Air velocity, the air flow rate and the turbulence of kinetic energy inside the room are important in the three simulations, but in the second simulation (room of $4 \mathrm{~m}$ ), the air velocity and the air flow rate are high and stable, that's allows to cool more the room. This different of values in the three simulations insure the need to specify the dimensions of the solar chimney to each room dimensions. So, in that case the solar chimney with the width of $0.3 \mathrm{~m}$ is optimum to the room of $4 \mathrm{~m}$ in dimensions.

\section{References}

1. E. Bacharoudis, MG. Vrachopoulos, MK. Koukou, D. Margaris, AE. Filios, SA. Mavrommatis, Study of the natural convection phenomena inside a wall solar chimney with one wall adiabatic and one wall under a heat flux. Appl ThermEng. (2007);27:2266-75.

2. G. Mekkawi, R Elgendy, solar chimney for enhanced natural ventilation based on CFDsimulation for a housing prototype in Alexandria, egypt, International Journal of Advances in Mechanical and Civil Engineering, ISSN: 2394-2827 Volume-3, Issue-5, Oct.-(2016) 
3. N.F.M. Kasim, S.A. Zaki, M.S.M . Ali, N. Ikegaya, A.A. Razak, Computational Study on the Influence of Different Opening Position on Wind- Induced Natural Ventilation in Urban Building of Cubical Array, Procedia Engineering 169 (2016) 256263

4. I. Zavala-Guillén, J. Xamán, I. Hernández-Pérez, M. GijónRivera, Y. Chávez, Numerical study of the optimum width of a diurnal double air-channel solar chimney, Energy (2018)

5. T. Miyazaki, A. Akisawa, T. Kashiwagi, The effects of solar chimneys on thermal load mitigation of office buildings under the Japanese climate, Renew. Energy 31(2006) 9871010.

6. J. Arce, M.J. Jimenez, J.D. Guaman, M.R. Heras, G. Alvarez, J. Xaman, Experimental study for natural ventilation on a solar chimney, Renew. Energy 34(2009) 2928-2934.

7. C. Jiménez-Xamàn, J. Xamàn,M. Gijon-Rivera, I. Zavala-Guillén, F. Noh-Pat, E. Simà, Asessing the thermal performance of a rooftop solar chimney attached to a single room, Journal of Building Engineering (2020)

8. Cheng, X., Shi, L., Dai, P., Zhang, G., Yang, H., Li, J. : Study on Optimizing Design of Solar Chimney for Natural Ventilation and Smoke Exhaustion, Energy \& Buildings (2018)

9. Kong, J., Niu, J., Lei, C.: A CFD based approach for determining the optimum inclination angle of a roof-top solar chimney for building ventilation, Solar Energy, Elsevier (2020)

10. Villagran EA, Baeza Romero EJ, Bojaca CR Transient CFD analysis of the natural ventilation of three types of greenhouses used for agricultural production in a tropical mountain climate. Biosyst Eng 188:288-304. (2019)

11. Laila M, Zandi M, Bidi M, Behroozizade E, Kazemi I. New design for solar chimney with integrated windcatcher for space cooling and ventilation. Build Environ. https://doi.org/10.1016/j.build env.2020.10678 5. 2020.

12. Ahmed Abdeen, A.A., Serageldin, M.G.E., Ibrahim, A., El- Zafarany, S. and Ookawara, R.M., "Solar chimney optimization for enhancing thermal comfort in Egypt: an experimental and numerical study”, Solar Energy, Vol. 180, pp. 524-536, (2019) doi: 10.1016/j.solener.2019.01.063.

13. Nguyen YQ, Wells JC. A numerical study on induced flowrate and thermal efficiency of a solar chimney with horizontal absorber surface for ventilation of buildings. $\mathrm{J}$ Build Eng. 2020;28:1-31.

14. Sheikh Saiful Azam Samsudin, Abdul Muin Shaari, Kamil Abdullah, Mohd Faizal Mohideen Batcha, Potential of Utilizing Solar Chimney as an Energy Efficiency Measure in Malaysian Hospitals , CFD Letters: Vol. 12 No. 4: April (2020)

15. Kashyap.S, Kumar.G.V, Kumar.T.A, Enhancing Passive Cooling and Natural Ventilation for Houses of Various Climatic Zones of India, 2nd International Conference on Power and Energy Applications, 978-1-7281-1596-2/19/\$31.00 (C2019 IEEE

16. B. Brangeon 'Contribution à l'étude numérique de la ventilation naturelle dans des cavités ouvertes par la simulation des grandes échelles. Application au rafraichissement passif des bâtiments' $\mathrm{PhD}$ thesis in Mechanics and Building Sciences, University of Reunion (2012) 